\title{
Regenerated Waste Tire Powders as Fillers for Wood Fiber Composites
}

\begin{abstract}
Xinwu $\mathrm{Xu},{ }^{\mathrm{a}, *}$ Feiyu Tian, ${ }^{\mathrm{a}}$ and Xiaoke $\mathrm{Li}^{\mathrm{b}}$
Waste rubber retains good elasticity and can be regenerated for use in special applications. In this research, wood fiber composites were made with waste tire powders (WTPs) as functional fillers. The physicalmechanical properties of the wood-rubber composite (WRC) panels, i.e., inner bond (IB) strength, static bending modulus (MOE), strength (MOR), and thickness swelling (TS) were assessed. The surface micromorphology of the WRC panels was quantitatively analyzed and was graphically simulated with Matlab software. The results showed that WTPs decreased the mechanical strength and modulus of the hybrid composites, which was caused by the weak fiber/WTP interfacial adhesion. The addition of WTPs roughened the surface of composite panels. However, WRC panels showed improved hygroscopic stability and flexibility compared to pure wood fiber composites. Sanding can flatten the rougher WRC panel surface; however, it brings tiny pits to the surface that are caused by loss of rubber powders. Surface overlaying with resin impregnated paper was found to be effective to cover the tiny pits. This study showed that it is feasible to make value added rubber filled wood fiber composites with satisfactory performance.
\end{abstract}

Keywords: Waste rubber; Wood-rubber composite; Surface characteristics; Overlaying

Contact information: a: College of Materials Science and Engineering, Nanjing Forestry University, Nanjing, China 210037; b: Nanxun Quality Inspection Institute of Wood Products, Nanxun, China 311202;

*Corresponding author: xucarpenter@aliyun.com

\section{INTRODUCTION}

Waste rubber products such as out-of-service vehicle tires, which traditionally are discarded and piled up in open air, have aroused increasing concerns around the world. In China, waste tires increase by 8 to 10 percent annually, which is up to nearly 379 million pieces or 14.59 million tons in 2018. Policies were unveiled to encourage recycling and reutilizing of these resources with the reusing percentage of about 65\% (SCPRC 1996).

Recycled rubber still maintains its elastic, damping, and water repellent properties, and is cost saving. Currently, recycled rubber mainly flows back to its original industry after necessary cleaning, fixing, or refining (Yao et al. 2009). As well, recycled rubber is gradually arousing interest in other industries. Typically, it is mixed into concrete or asphalt for construction of highways, sport tracks, or airplane runways (Segre and Joekes 2000; Li et al. 2004). In these cases, waste rubber products such as tires should be milled to small particles of 120 to $200 \mathrm{mesh} / \mathrm{in}$ (or 0.075 to $0.12 \mathrm{~mm}$ ) aided by special processes such as frozen milling. However, value-added applications of waste rubber resources are still insufficient to make full use of the resource, and more innovative technologies are needed.

Wood composites are overwhelmingly used for furniture, floorings, walls, ceilings, and inner decorations. In those applications, thermoset synthetic adhesives such as urea or phenolic-formaldehyde (UF, PF) resins are normally used as adhesives. After curing, these

Xinwu Xu. (2020). "Rubber-filled wood fiber compos.," BioResources 15(2), 3029-3040. 3029 
synthetic resins tend to be irreversibly stiff and crisp, which brings difficulty to smoothly cutting or sawing, and decreases the flexibility or damping performance of wood composites.

Adding rubber units may help solve the above problems. Research by Aoudia et al. (2016) showed that recycled rubber as a functional modifier to thermoset polymers led to higher impact strength. Other investigations also showed that addition of rubber into wood composites can reinforce the damping, energy absorbing, water repellent, anti-rot, and electrical insulating properties (Song 1995; Yang et al. 2004; Ichazo et al. 2006; Li et al. 2007; Zhao et al. 2008, 2010; Ayrilmis et al. 2009a, b; Sun 2009).

Since rubber and wood have different surface characteristics, i.e., rubber is hydrophobic while wood is hydrophilic, surface modification to waste rubber units is essential before composition with wood. The methods include pre-treatment with coupling agents (acryloyl chloride, Bai 2009; titanate, Li et al. 2007; silane, Wu et al. 2011), or mechanical grinding or rolling rubber units (Li et al. 2007), which help improve the interfacial bonding between rubber and wood units.

Waste rubber particles (normally black in color) may fail to bring an aesthetic appearance to wood-rubber composites (WRC). Surface decoration is needed before they are put into use. This study, therefore, was conducted to fabricate a composite of wood fibers and waste tire powders (WTPs) decoratively overlaid with resin-impregnated papers. The influence of the content and size of WTPs on the physical, mechanical, and surface properties of WRC panels were specifically analyzed.

\section{EXPERIMENTAL}

\section{Materials}

Poplar (Populus euramericana cv. 'I-214') wood fibers were supplied by the New Concept Wood Corporation (Shuyang, China). Vaporized wood chips (20 to $30 \mathrm{~mm}$ long, 10 to $15 \mathrm{~mm}$ wide, and 4 to $6 \mathrm{~mm}$ thick) were industrially milled into fibers following the thermo-mechanical pulping (TMP) process adopted in the fiberboard or paper industry. The fibers were air dried to a moisture content (MC) of 9\%. Sieve analysis of the dried fibers was: larger than $1.7 \mathrm{~mm}$ (or $10 \mathrm{mesh} / \mathrm{in}$ ) - $18 \%, 0.15$ to $1.18 \mathrm{~mm}$ (or 14 to 100 mesh/in) - 65\%, and smaller than $0.15 \mathrm{~mm}$ of dried fibers (100 mesh/in) $-17 \%$.

Waste tire powders (WTPs) with dimensions of 0.55 to $1.09 \mathrm{~mm}$ (or 15 to 30 mesh/in) were acquired from Dongyang Rubber Co. Ltd (Nanjing, China). The impurities originally adhered in tires were separated during powder preparation. The powders were conditioned at $65 \%$ relative humidity $(\mathrm{RH})$ and $20{ }^{\circ} \mathrm{C}$ for two weeks before panel manufacturing. Silane (bis-( $\gamma$-triethoxysilylpropyl)-tetrasulfide), commercially marked as Si69, was used as the rubber coupling agent. An addition content of Si69 was $1 \%$ based on the weight of rubber powders.

Three layers of resin-impregnated paper were used to overlay the WRC panels (Fig. 1). The transparent layer on the top surface (i.e., wear-resistant paper) was impregnated with $150 \%$ low molecular melamine formaldehyde $(\mathrm{MF})$ resin (based on oven dry weight of the original paper). The paper contains $48 \mathrm{~g} / \mathrm{m}^{2}$ of aluminum oxide $\left(\mathrm{Al}_{2} \mathrm{O}_{3}\right.$, acting as the wear resisting agent). The second layer (i.e., decorative paper) contained $120 \% \mathrm{MF}$ resin. The bottom layer (i.e., backing balance paper) was impregnated with PF resin with a dark yellow color. 


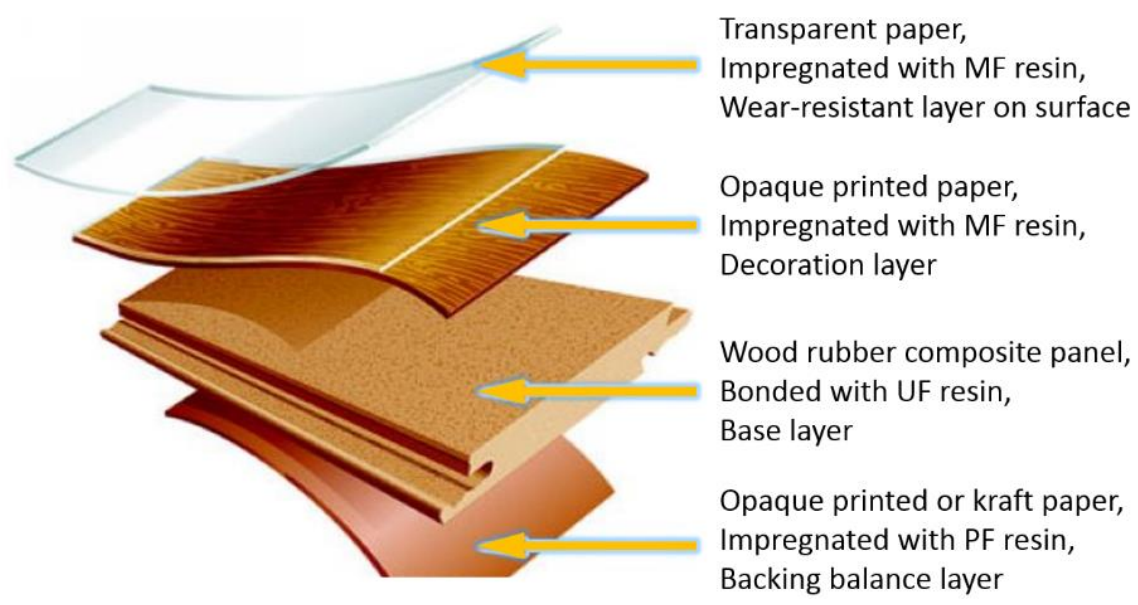

Fig. 1. Schematic construction of an overlaid wood rubber composite panel, typically used as public floorings.

The binder of WRC panels was UF resin. The concentration of the resin was $49.35 \%$ with a viscosity of $24 \mathrm{mPa} . \mathrm{s}\left(20^{\circ} \mathrm{C}\right)$. Ammonium chloride $\left(\mathrm{NH}_{4} \mathrm{Cl}\right)$ at $1 \%$ level based on UF resin solid was used as the curing agent.

\section{Methods}

WRC panel manufacturing, sanding, and overlaying

To disclose the influence of rubber powder size on the surface roughness and the physical-mechanical properties of WRC panels, the WTPs were sieved into three groups, i.e., 0.55 to $0.70 \mathrm{~mm}$ (or 25 to $30 \mathrm{mesh} / \mathrm{in}$ ), 0.70 to $0.85 \mathrm{~mm}$ (or 20 to $25 \mathrm{mesh} / \mathrm{in}$ ), and 0.85 to $1.10 \mathrm{~mm}$ (or 15 to $20 \mathrm{mesh} / \mathrm{in}$ ). Rubber powders from each group were pretreated with Si69 coupling agent and were uniformly mixed with wood fibers in a lab scale blender. Three wood to rubber ratios were used, i.e., 90:10, 80:20, and 70:30 (based on oven-dry weight).

Liquid UF resin was sprayed onto wood-rubber mixtures by compressed air using an electrically driven agitator at a content of $10 \%$ (based on the total weight of oven-dry wood/rubber materials). The glued hybrid was formed into loose mats with a frame box and was hot pressed into $600 \mathrm{~mm}$ by $600 \mathrm{~mm}$ by $12 \mathrm{~mm}$ panels under $3.5 \mathrm{MPa}$ at $160{ }^{\circ} \mathrm{C}$ for $6 \mathrm{~min}$. The target panel density was $0.90 \mathrm{~g} / \mathrm{cm}^{3}$. A repetition level of 3 was used for each condition. To compare, $100 \%$ wood fiber panels were also made.

All the WRC panels were sanded sequentially using a lab-scale belt sander after conditioning at room temperature at $65 \%$ relative humidity for $48 \mathrm{~h}$. The sanded panels were laminated with resin-impregnated papers into a four-ply construction as shown in Fig. 1. The overlaying process was finished under $2.0 \mathrm{MPa}$ at $180^{\circ} \mathrm{C}$ for 30 seconds.

\section{Physical and mechanical properties}

After conditioning, all virgin and overlaid panels were cut into specimens to test the bending modulus (MOE) and strength (MOR), inner bond (IB) strength, and thickness swelling (TS), according to the Chinese national standard for properties testing methods of wood-based panels (GB/T17657, GAQSIQ 1999). The MOR, MOE, and IB strength testing were conducted using a Sans Universal tester (CMT5504, Shenzhen, China). For the MOR and MOE test, the specimens (290 $\mathrm{mm}$ by $50 \mathrm{~mm}$ thickness) were loaded at the mid-length following the three-point mode with the crosshead moving at $5 \mathrm{~mm}$ per min. 
The span for center loading was 20 times the thickness (i.e., $240 \mathrm{~mm}$ ). The IB strength specimens ( $50 \mathrm{~mm}$ by $50 \mathrm{~mm}$ thickness) were steadily pulled perpendicular to the surface at a uniform rate in a tensile mode, until the samples were split in the thickness direction. To test the TS properties, water soaking was conducted. Specimens, nominally $50 \mathrm{~mm}$ by $50 \mathrm{~mm}$ thickness, were submersed horizontally under $10 \mathrm{~mm}$ of water at room temperature for $24 \mathrm{~h}$. The center-point thickness of the specimens before and after soaking was measured to calculate the swelling rate, i.e., the increased thickness divided by the initial thickness.

\section{Surface structure of WRC panels}

A stereoscopic microscope (Leica S8AP0, Wetzlar, Germany) with a focus range of $135 \mathrm{~mm}$ and magnification range $\times 10$ to $\times 80$ was used to analyze the interface between rubber powders and wood fibers.

\section{In-thickness flexibility of composite panels}

To analyze the influence of rubber units on the flexible performance of WRC panels, a four-cycle compressive loading and unloading test was conducted using a Sans Universal tester (CMT5504, Shenzhen, China). Specimens, $30 \mathrm{~mm}$ by $20 \mathrm{~mm}$ thickness, were compressed perpendicular to the surface at a loading rate of $3 \mathrm{~mm} / \mathrm{min}$. The ending load for every cycle was controlled at $6 \mathrm{kN}$. The output load-displacement curve $(L-D$ curve) was plotted. The linear stage of each $L-D$ curve can be described mathematically as follows,

$$
L=f \cdot D+c
$$

where, $f$ is the slope value reflecting the stiffness under compression $(\mathrm{kN} / \mathrm{mm})$ and $c$ is a constant $(\mathrm{kN})$.

\section{Overlaying performance}

Samples of $50 \mathrm{~mm}$ by $50 \mathrm{~mm}$ thickness were cut from overlaid panels to test the surface bond (SB) strength between decorative paper and the WRC substrate with a Sans Universal tester (CMT5504, Shenzhen, China). A $20 \mathrm{~mm}$ by $20 \mathrm{~mm}$ square at center was separated from the whole sample surface by cutting a $2 \mathrm{~mm}$ wide groove with the top two layers of paper exactly cut away. A tensile force perpendicular to panel surface was then exerted. In that way, the tension will be focused and the panel damage occurs at the separated part. Loading speed was controlled as $1 \mathrm{~mm} / \mathrm{min}$.

\section{Surface roughness}

Roughness testing was conducted by moving a stylus along a line on the surface of the test object for a designated distance (Candan et al. 2010). The vertical displacement of the stylus tip is output as a continuous curve containing numerous peaks or valleys. The mean arithmetic deviation of profile $\left(R_{a}\right)$ can be calculated presenting the surface roughness. This method is limited to a line and fails to present the roughness of a whole surface.

In this study, a modified measuring method was applied (Fig. 2). Specimens (100 $\mathrm{mm}$ by $100 \mathrm{~mm}$ by thickness) were gridded following Fig. 2a with 100 points marked. A digital profilometer was applied to acquire the $R_{a}$ data. Each measurement was conducted with the stylus tip travelling $0.25 \mathrm{~mm}$ with point $(i, j)$ as the middle point. An exemplified trace of the stylus tip centering point $(i, j)$ is shown in Fig. $2 \mathrm{~b}$, from which the roughness 
data $R_{a}(i, j)$ is acquired. In total, 100 measurements were conducted and $100 R_{a}(i, j)$ data points were acquired representing the roughness of 100 positions on the specimen surface.

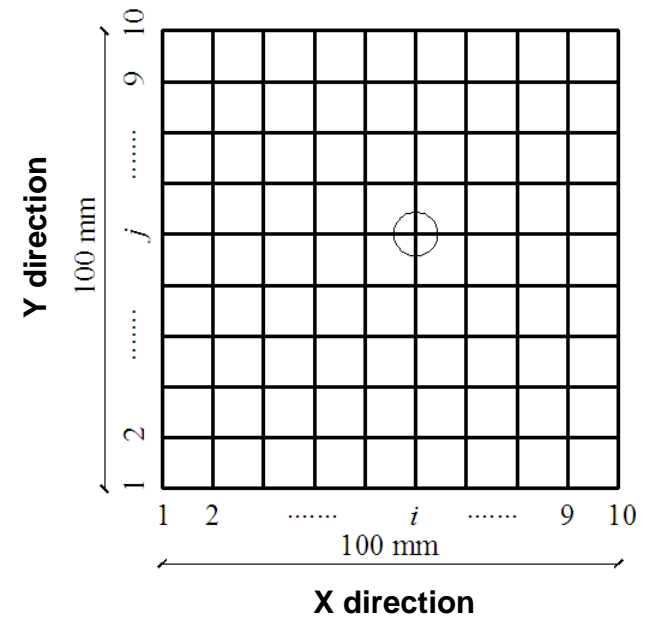

(a) Testing area

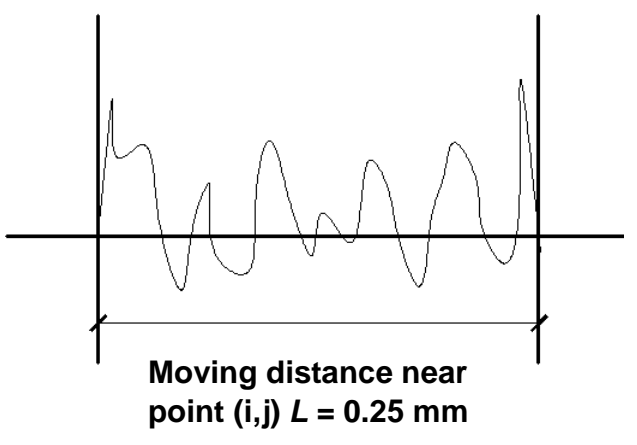

(b) Trace of tylus tip movement

Fig. 2. Schematıc alagram or vV Ku paneı surtace rougnness testıng

With all the $R_{a}(i, j)$ data, the micro-morphology for the whole surface of a specimen was graphically plotted with use of the Matlab software (version 2018a, The MathWorks), following the codes below:

$M=\left[i, j, R_{a}(i, j)\right] ;$ /the tested points as a 3-dimensional matrix/

$x=M(:, 1) ;$ /position ' $i$ ' in $x$-direction/

$y=M(:, 2) ; /$ position ' $j$ ' in $y$-direction /

$z=M(: 3) ; / R_{a}(i, j) /$

$[X, Y, Z]=\operatorname{griddata}(x, y, z)$;

$\operatorname{surf}(X, Y, Z)$.

All $R_{a}(i, j)$ data of a specimen were averaged to $R_{a v g}$ as follows,

$$
R_{a v g}=\frac{1}{m^{*} n} \sum_{i=1, j=1}^{m=10, n=10} R_{a(i, j)}
$$

where, $m$ and $n$ are the total quantity of measured points in $\mathrm{x}$ and $\mathrm{y}$ directions, as shown in Fig. 2a.

The coefficient of variation among all measured positions, $C V_{R a}$, was calculated as follows to assess the roughness difference in a specimen,

$$
C V_{R a}=\frac{1}{R_{\text {avg }}} \sqrt{\frac{\sum\left(R_{a(i, j)}-R_{a v g}\right)^{2}}{m^{*} n-1}}
$$




\section{RESULTS AND DISCUSSION}

\section{Physical-mechanical Properties}

The addition of rubber powders into wood fiber composites evidently improved the hygroscopic stability while weakening the mechanical performance (Table 1). Higher content and/or larger size of rubber powders led to lower TS, IB, MOR, and MOE values. The results were highly coincident to former studies (Song 1995; Yang et al. 2004; Zhao et al. 2008, 2010; Ayrilmis et al. 2009a,b), which can be attributed to the changed bonding interface caused by rubber powders. Figure 3 shows that tiny separation of rubber powders from wood fibers exists. This may weaken the bonding strength. The lower TS values of WRC panels were attributed to the hydrophobicity of rubber and the closer wood-rubber contact.

Table 1. Physical and Mechanical Properties of WRC Panels before Overlaying

\begin{tabular}{|c|c|c|c|c|c|c|}
\hline $\begin{array}{c}\text { Rubber } \\
\text { content } \\
(\%)\end{array}$ & $\begin{array}{c}\text { Rubber } \\
\text { Size } \\
(\mathrm{mesh} / \mathrm{in})\end{array}$ & $\begin{array}{c}\text { Density } \\
\left(\mathrm{g} . \mathrm{cm}^{-3}\right)\end{array}$ & $\begin{array}{c}\text { IB Strength } \\
(\mathrm{MPa})\end{array}$ & $\begin{array}{c}\text { TS } \\
(\%)\end{array}$ & $\begin{array}{c}\text { MOR } \\
(\mathrm{MPa})\end{array}$ & $\begin{array}{c}\text { MOE } \\
(\mathrm{MPa})\end{array}$ \\
\hline 0 & - & 0.90 & $1.55(0.36)$ & $5.5(0.02)$ & $35.51(6.07)$ & $2662.6(373.34)$ \\
\hline \multirow{3}{*}{10} & $15-20$ & 0.87 & $1.47(0.35)$ & $5.7(0.01)$ & $21.35(3.82)$ & $1481.2(332.96)$ \\
\cline { 2 - 7 } & $20-25$ & 0.88 & $1.51(0.29)$ & $5.6(0.01)$ & $26.23(2.49)$ & $1590.4(193.95)$ \\
\cline { 2 - 7 } & $25-30$ & 0.87 & $1.56(0.36)$ & $5.9(0.01)$ & $23.6(6.60)$ & $1705.0(518.87)$ \\
\hline \multirow{3}{*}{20} & $15-20$ & 0.86 & $1.19(0.12)$ & $4.7(0.01)$ & $15.32(3.64)$ & $1036.3(277.09)$ \\
\cline { 2 - 7 } & $20-25$ & 0.85 & $1.27(0.24)$ & $5.0(0.01)$ & $18.79(3.09)$ & $1201.2(150.01)$ \\
\cline { 2 - 7 } & $25-30$ & 0.84 & $1.24(0.25)$ & $4.8(0.01)$ & $19.3(5.20)$ & $1148.9(311.43)$ \\
\hline \multirow{3}{*}{30} & $15-20$ & 0.88 & $1.17(0.36)$ & $4.7(0.01)$ & $12.88(4.28)$ & $828.0(303.53)$ \\
\cline { 2 - 7 } & $20-25$ & 0.87 & $1.12(0.30)$ & $5.2(0.01)$ & $15.21(2.00)$ & $867.91(43.30)$ \\
\cline { 2 - 7 } & $25-30$ & 0.82 & $0.86(0.24)$ & $3.3(0.01)$ & $12.9(3.99)$ & $838.93(02.36)$ \\
\hline
\end{tabular}

Note: All data in brackets were standard deviation values of 9 specimens for density, TS, and $\mathrm{IB}$, and 6 specimens for MOR and MOE.
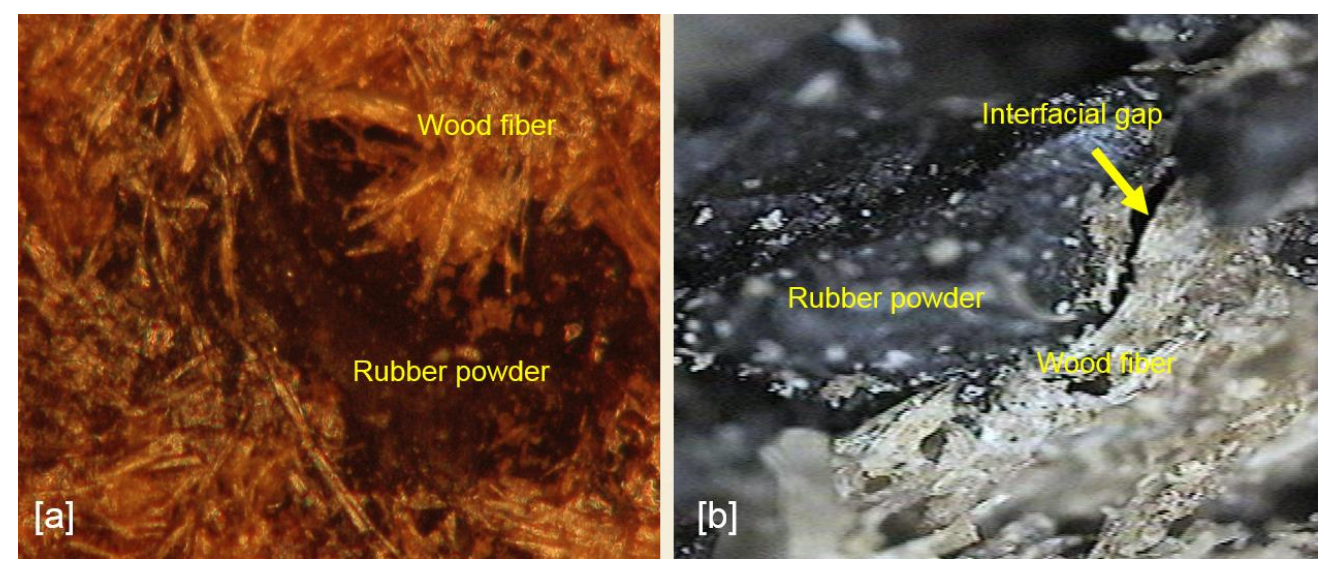

Fig. 3. Surface structure of WRC panels $(\times 10)[a]$ and interfacial gap between wood fibers and rubber powders $(\times 80)[b]$

Xinwu Xu. (2020). "Rubber-filled wood fiber compos.," BioResources 15(2), 3029-3040. 3034 
Rubber powders were squeezed to wood fibers during hot-pressing, which may help narrow the voids in the matrix and retard the process of moisture penetration. To compare, smaller rubber powders resulted in higher water repellence due to their larger specific surface area. Likewise, higher content of rubber powders led to lower TS values as well.

Figure 4 discloses the differential mechanical behaviors of different panels under a static bending load. Breakage of wood fiber panel specimens happened sharply when the maximum load was reached. WRC panel specimens, however, failed without evident breakage, mainly in the form of surface wrinkles around the loading position. The addition of rubber powders in fiber panels led to lower MOR and MOE values. This means that rubber-filled panels exhibited higher elasticity than pure wood fiber panels. At a same addition content (e.g., 20\%, Fig. 4 and Table 1), smaller rubber powders resulted in higher strength to WRC panels, which may be due to the better wood-rubber interfacial contact.

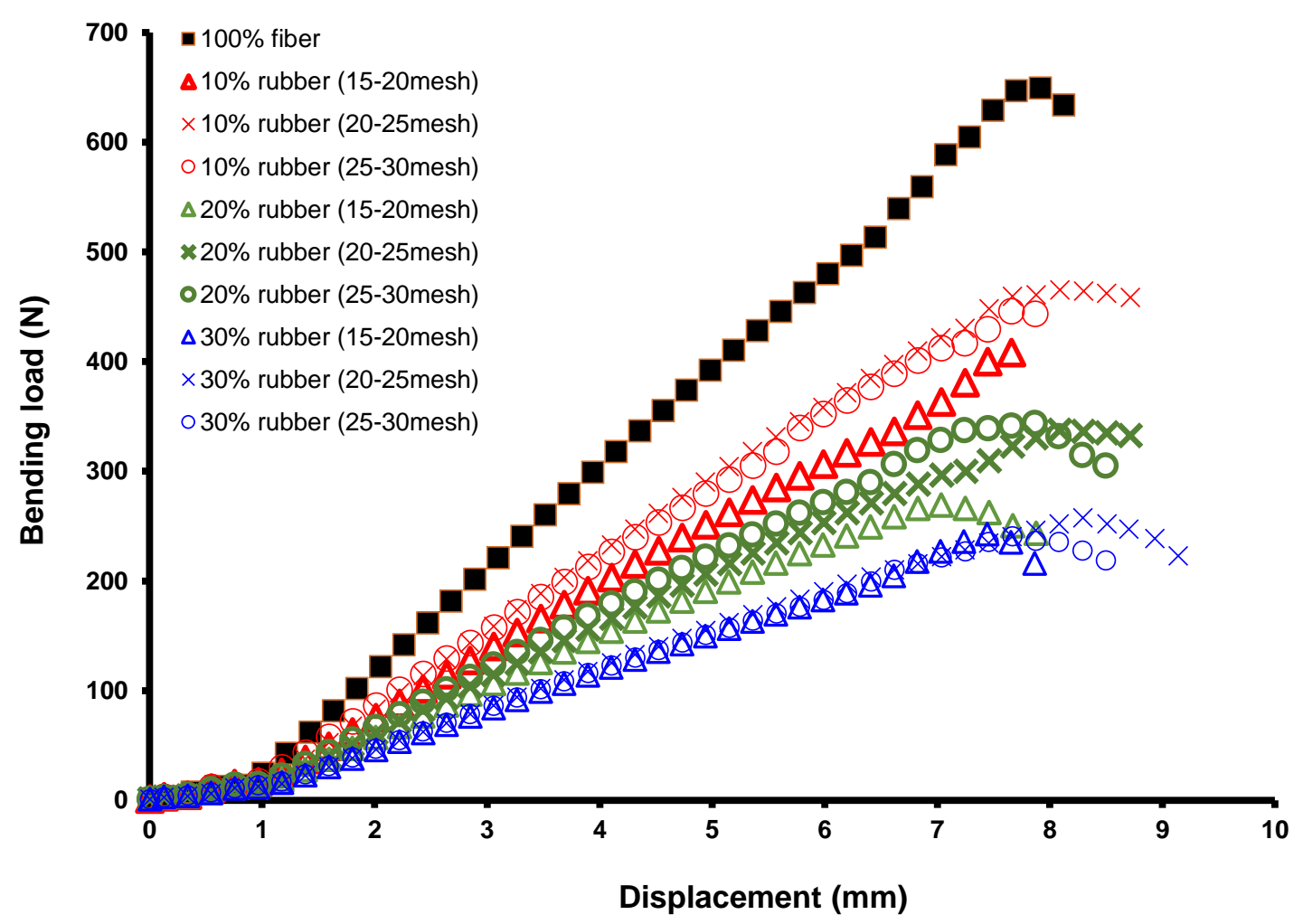

Fig. 4. Bending load-displacement curves of wood fiberboard and WRC panels without overlaying For each condition, the data plotted were average values for 6 specimens. To simplify, one from five continuous tested data was used to plot the discrete load-displacement curves.

The properties of overlaid WRC panels with $10 \%$ rubber powders are shown in Table 2. Compared with overlaid pure wood fiberboards, overlaid WRC panels exhibited decreases in TS, IB strength, MOR, and MOE values. However, the surface bond strength was comparable. Hence, addition of $10 \%$ rubber powders had no evident influence on adhesion between resin-impregnated paper and substrate panels. The WRC panels with 15 to $20 \mathrm{mesh} /$ in rubber powders had the highest $\mathrm{SB}$ value $(0.78 \mathrm{MPa})$. 
Table 2. Exemplified Physical and Mechanical Properties of Overlaid WRC Panels Filled with $10 \%$ Rubber Powders

\begin{tabular}{|l|c|c|c|c|}
\hline \multirow{2}{*}{ Property } & Control & \multicolumn{3}{|c|}{ WRC Panels (10\% rubber plus 90\% wood fibers) } \\
\cline { 3 - 5 } & $(100 \%$ wood fibers) & $15-20$ mesh/in & $20-25$ mesh/in & $25-30$ mesh/in \\
\hline Density $\left({\left.\mathrm{g} . \mathrm{cm}^{-3}\right)}^{-3}\right.$ & $0.91(0.08)$ & $0.88(0.04)$ & $0.89(0.07)$ & $0.90(0.12)$ \\
\hline TS (\%) & $2.86(0.17)$ & $2.68(0.07)$ & $2.10(0.03)$ & $0.79(0.08)$ \\
\hline IB strength (MPa) & $0.95(0.06)$ & $0.65(0.16)$ & $0.67(0.03)$ & $0.63(0.17)$ \\
\hline MOR (MPa) & $19.81(7.78)$ & $13.12(1.88)$ & $14.06(5.10)$ & $18.94(5.53)$ \\
\hline MOE (MPa) & $3649(82.7)$ & $3423(22.8)$ & $2436(66.6)$ & $2889(26.7)$ \\
\hline $\begin{array}{l}\text { SB strength } \\
\text { (MPa) }\end{array}$ & $0.75(0.03)$ & $0.70(0.18)$ & $0.78(0.04)$ & $0.71(0.08)$ \\
\hline $\begin{array}{l}\text { Note: All data in brackets in the table were standard deviation values of 9 specimens for } \\
\text { density, TS, IB, and SB, and 6 specimens for MOR and MOE. }\end{array}$
\end{tabular}

\section{In-thickness Flexibility}

The flexibility in the thickness direction is crucial for a composite panel applied in fields like sport flooring, where high energy absorption is needed against momentary and impetuous impact. Addition of rubber powders in wood fiber composites significantly improves the flexibility, which shows more compressive deflection in thickness (Fig. 5). Figure 6 shows that the $f$-value increased with loading and unloading cycles for wood fiber panels while WRC panels showed decreased $f$-values. This can be explained by the various inborn characteristics of wood and rubber. Wood is viscoelastic. Thus, irrecoverable plastic deformation may occur under cyclic compression loadings, while rubber (also called "elastomer") can easily recover once unloaded. After cycles of compression, wood fiber panels become denser and stiffer (see increased $f$ values in Fig. 6). WRC panels get denser as well (which means wood fiber and rubber powders contact closer), but rubber units may act more effectively. Hence, WRC panels perform even more elastically after repeated compression loads. This feature is advantageous for WRC panels.

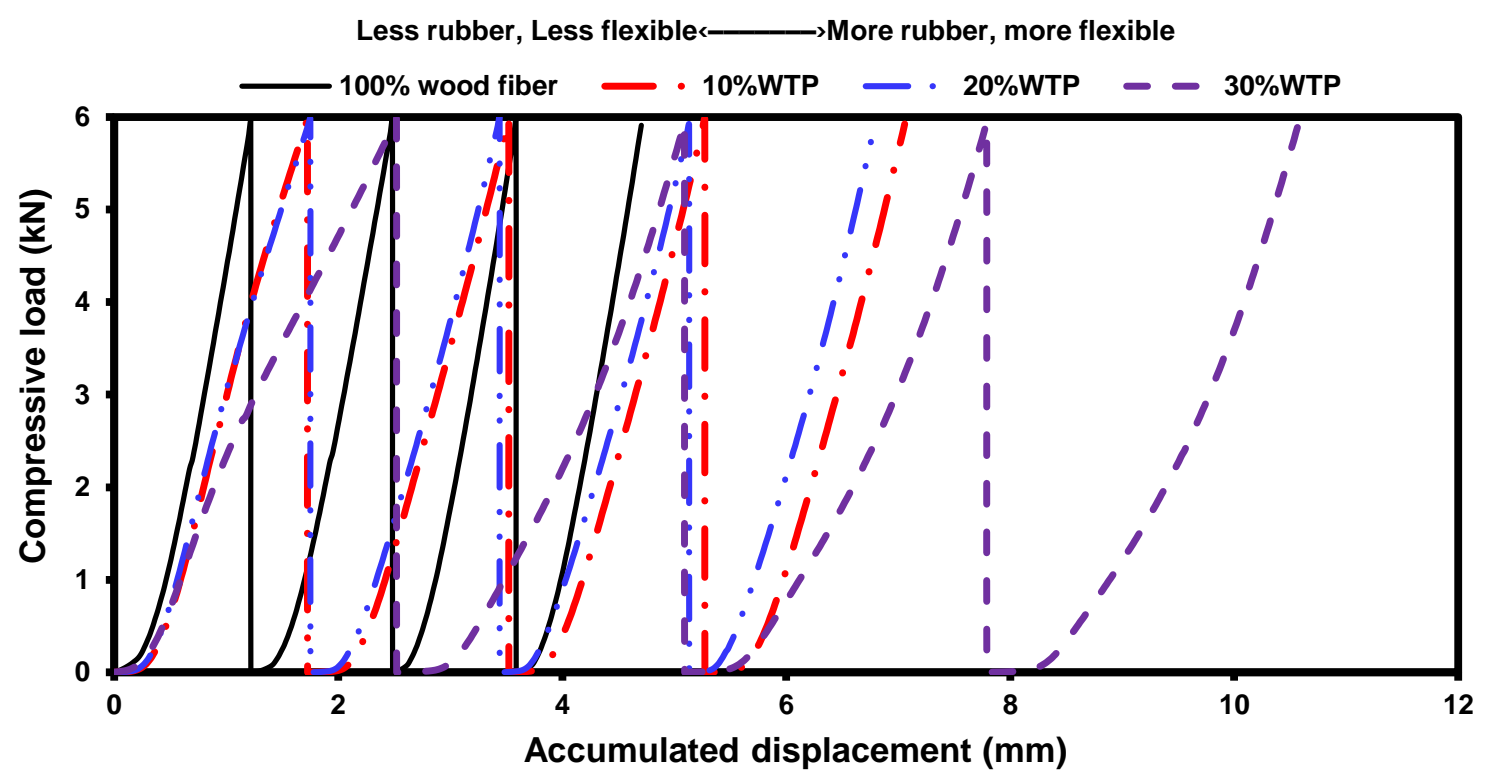

Fig. 5. Load-displacement curves of different panels under four cycles of compressive loading and unloading (WTP size: 15-20 mesh/inch) 


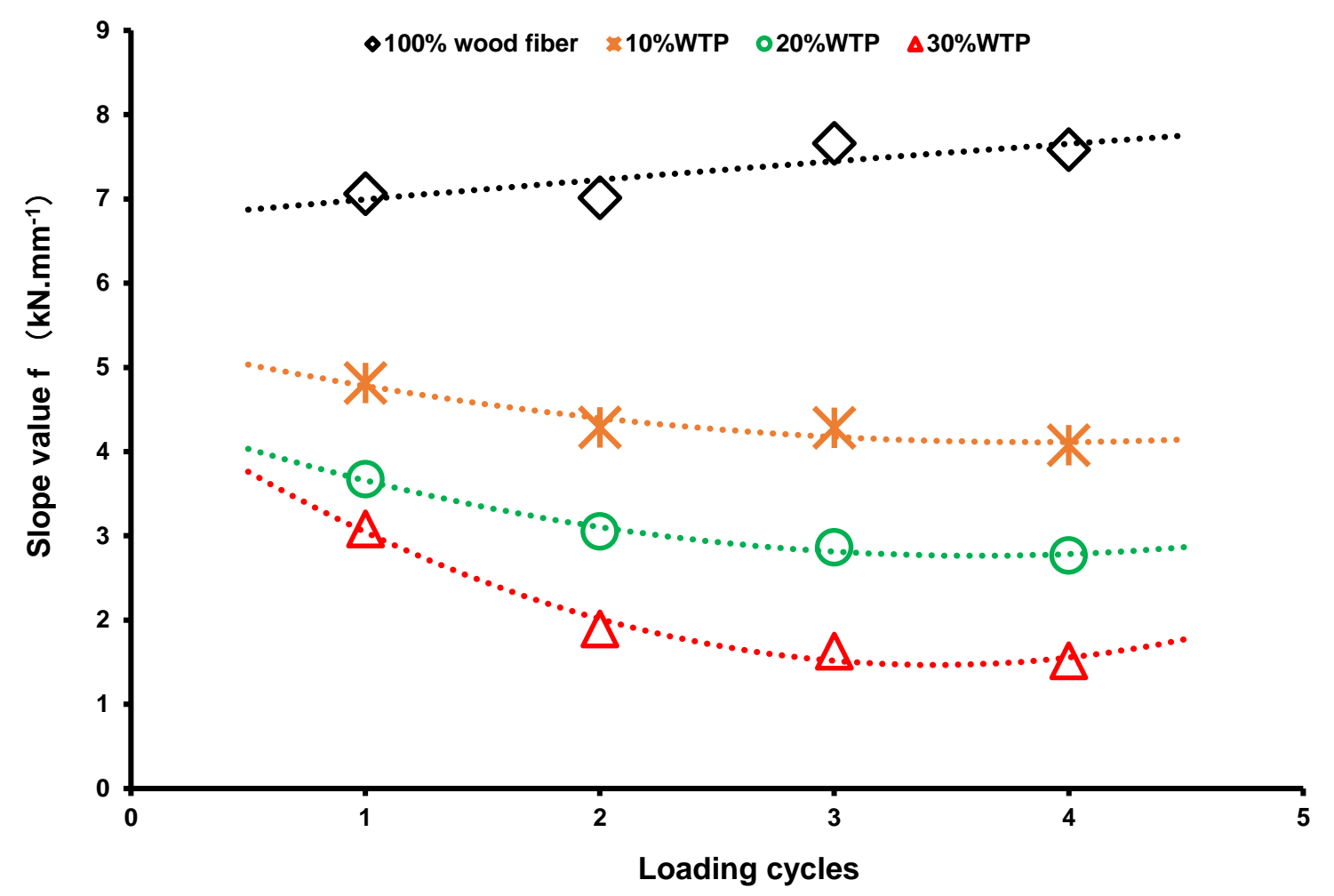

Fig. 6. Slope values $(f)$ of load-displacement curves in linear stage (Fig. 5) for different composite panels as a function of loading and unloading cycles

\section{Surface Morphology}

Figure 7 presents the simulated micro-scale surface shapes of fiberboard and WRC panels before sanding. Pure wood fiber panels had an average roughness $\left(R_{\text {avg }}\right)$ of $2.89 \mu \mathrm{m}$, while WRC panels showed evidently higher $R_{\text {avg }}$ values of 3.52 to $4.82 \mu \mathrm{m}$.

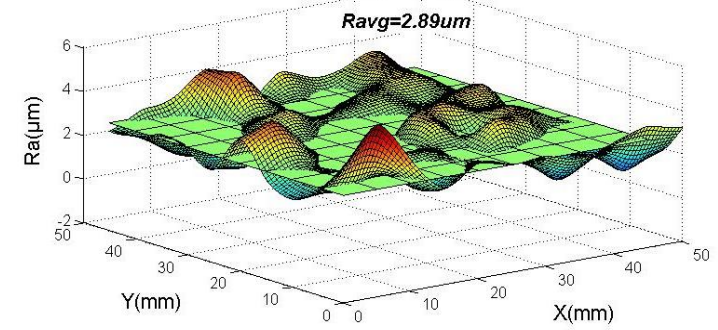

(a) $100 \%$ wood fiber

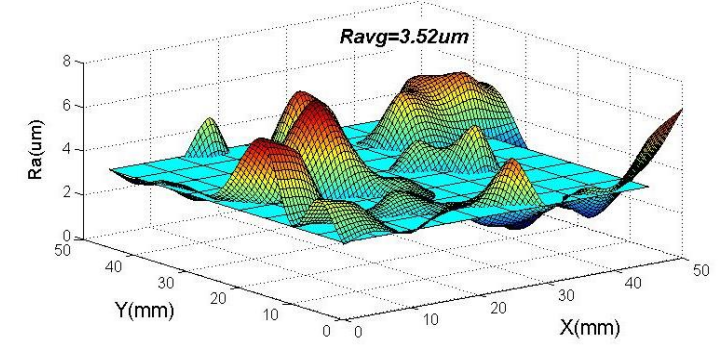

(c) $10 \%$ rubber (20-25 meshes/in)

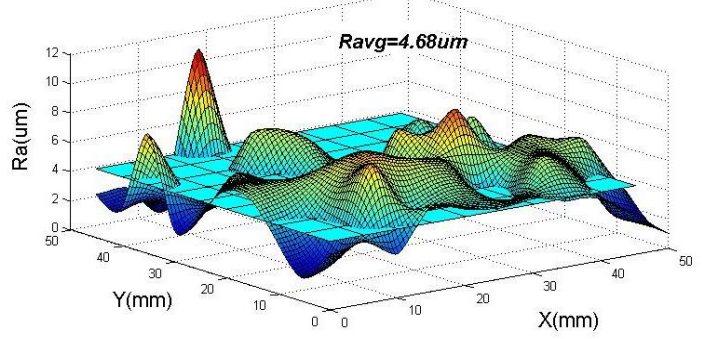

(b) $10 \%$ rubber (15-20 meshes/in)

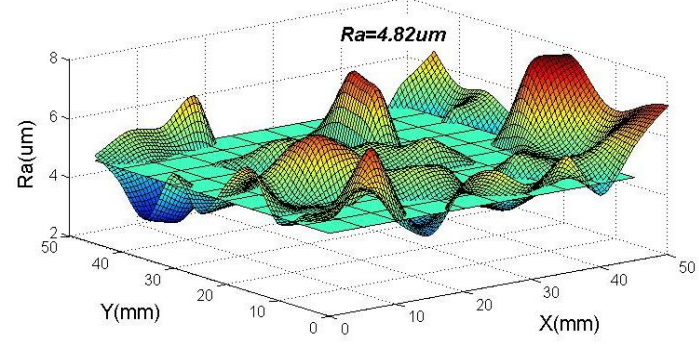

(d) $10 \%$ rubber (25-30 meshes/in)

Fig. 7. Simulated micro-scale shapes of panels before sanding using the Matlab software 
The addition of rubber powders in wood fiber composites unavoidably worsens the surface flatness. Initially, all panels were hot-compressed to a unique final thickness, e.g., $12 \mathrm{~mm}$ in this study. In this process, rubber powders were effectively compressed and showed elastic deformation. During conditioning in air, however, the rubbery substances are liable to spring back, especially the powders distributed in the surface layers of WRC panels. In contrast, wood fibers deform plastically under heat and pressure, resulting in little recovery. The differential recovery behaviors between rubber and wood fibers are finally embodied as larger $R_{\text {avg }}$ values of WRC panels than control. As well, addition of rubber powders in composites decreased the uniformity of surface flatness as well. The coefficient of roughness variation $\left(C V_{R a}\right)$ of the $100 \%$ wood fiber panel was 0.26 , while those for WRCs were 0.37 to 0.40 .

\section{Overlaying Performance}

Sanding of WRC substrates led to partial pull-out of rubber powders, leaving tiny pits on the panel surface. Statistically, the pits accounted for about 0.6 to $1.2 \%$ of the whole surface area. However, after overlaying by resin-impregnated paper, WRC panels showed better surface flatness than pure fiberboard (Fig. 8). The panels with 15 to 20 mesh/in rubber powders had the lowest $R_{\text {avg }}$ value of $1.26 \mu \mathrm{m}$, which was much better than the control $(2.24 \mu \mathrm{m})$. In addition, overlaid WRC panels were much smoother than the panels before sanding (Fig. 8 vs. Fig. 7). The $R_{a v g}$ values, 1.26 to $2.21 \mu \mathrm{m}$ (Fig. 8b, c, d), were nearly half of those shown in Fig. 7b, c, d. Therefore, the two layers of paper (wear-resistant and decorative layers) on WRC substrates are fully capable of covering the surface defects of sanded WRC panels. From Table 2, it is also shown that WRC panels have comparable surface bond strength to fiberboard. Hence, the pull-out of rubber powders during sanding has no evident influence on overlaying strength.

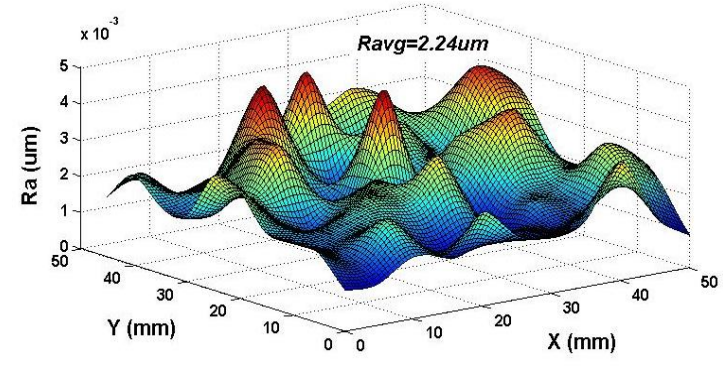

(a) $100 \%$ wood fiber

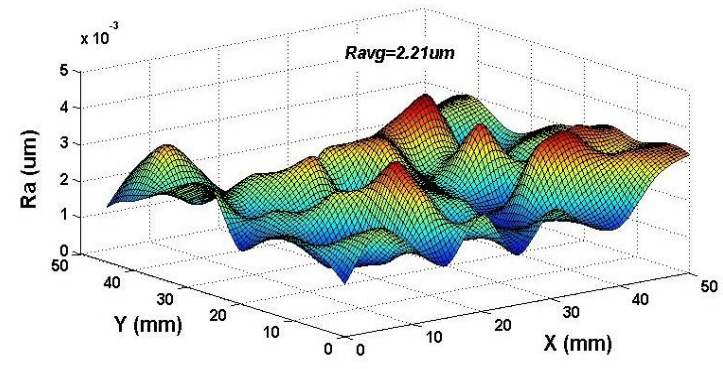

(c) $10 \%$ rubber $(20-25$ meshes/in)

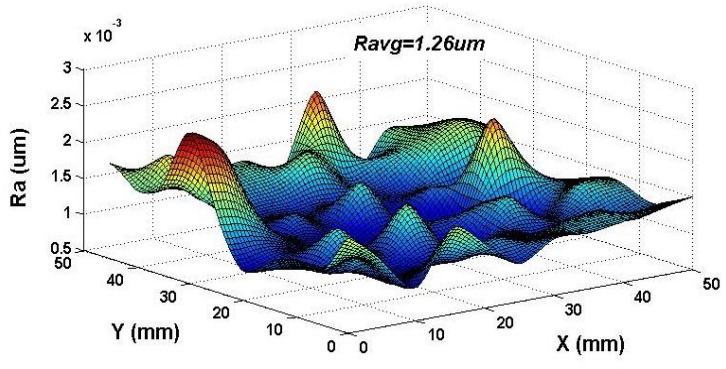

(b) $10 \%$ rubber (15-20meshes/in)

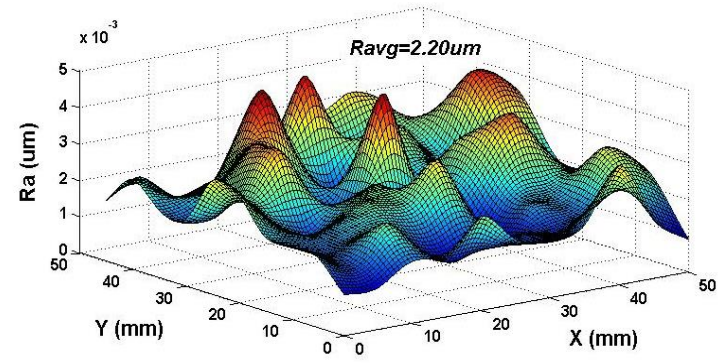

(d) $10 \%$ rubber (25-30meshes/in)

Fig. 8. Simulated micro shapes of WRC panels compared to wood fiber panels after overlaying using the Matlab software 


\section{CONCLUSIONS}

1. Utilization of recycled rubber to modify the strength and viscoelastic properties of wood fiber composites is feasible based on this research.

2. Addition of waste tire powders into wood fiber composite panels decreases the mechanical properties, roughens the surface, and may bring tiny pits during surface sanding, especially at higher content and/or using larger powder sizes. However, rubber fillers improve the hygroscopic stability and flexibility of WRC panels.

3. For practical applications such as sports floorings, resin-impregnated papers can be used to overlay the sanded WRC panels with satisfactory surface flatness and bond strength.

\section{ACKNOWLEDGMENTS}

This work was supported by the Zhejiang Provincial Key Investigation Program (No: 2017C01117), and the Analysis and Test Center of Nanjing Forestry University.

\section{REFERENCES CITED}

Aoudia, K., Azem, S., Hocine, N. A., Gratton, M., Pettarin, V., and Seghar, S. (2016). "Recycling of waste tire rubber: Microwave devulcanization and incorporation in a thermoset resin," Waste Management 60, 471-481. DOI:

10.1016/j.wasman.2016.10.051

Ayrilmis, N., Buyuksari, U., and Avci, E. (2009a). "Utilization of waste tire rubber in the manufacturing of particleboard," Materials and Manufacturing Processes 24(6), 688692. DOI: 10.1080/10426910902769376

Ayrilmis, N., Buyuksari, U., and Avci, E. (2009b). "Utilization of waste tire rubber in manufacture of oriented strand panel," Waste Management 29(9), 2553-2557. DOI: 10.1016/j.wasman.2009.05.017

Bai, W. (2009). New Application of Crystalline Cellulose in Rubber Composites, Ph.D. Dissertation, Oregon State University, Corvallis, OR, USA.

Candan, Z., Hiziroglu, S., and McDonald, A. G. (2010). "Surface quality of thermally compressed Douglas fir veneer," Materials and Design 31(7), 3574-3577. DOI: 10.1016/j.matdes.2010.02.003

GB/T17657 (1999). "Test methods of evaluating the properties of wood-based panels and surface decorated wood-based panels," General Administration of Quality Supervision, Inspection, and Quarantine of P.R. China (GAQSIQ).

Ichazo, M. N., Hernández, M., Albano, C., and González, J. (2006). "Curing and physical properties of natural rubber / wood flour composites," Macromolecular Symposium 239, 192-200. DOI: 10.1002/masy.200690096

Li, G. Q., Stubblefield, M. A., Garrick, G., Eggers, J., Abadie, C., and Huang, B. S. (2004). "Development of waste tire modified concrete," Cement and Concrete Research 34, 2283-2289. DOI: 10.1016/j.cemconres.2004.04.013

Li, K., Wen, F., Wang, D., Huang, J., and Zhan, X. (2007). "Study on the technology of wood-rubber composite panel," Wood Processing Machinery 4, 1-4. (in Chinese)

Xinwu Xu. (2020). "Rubber-filled wood fiber compos.," BioResources 15(2), 3029-3040. 3039 
Segre, N., and Joekes, I. (2000). "Use of tire rubber particles as addition to cement paste," Cement and Concrete Research 30, 1421-1425. DOI: 10.1016/S00088846(00)00373-2

Song, X. M. (1995). Wood Fiber and Recycled Tire Rubber Hybrid Composites, Ph.D. Dissertation, Michigan Technological University, Houghton, MI, USA.

Sun, W. (2009). Study on Wood-rubber Composites and Application in Soundproof Flooring, Ph.D. Dissertation, Beijing Forestry University, Beijing. (in Chinese)

The State Council of the People's Republic of China (SCPRC) (1996). Several Policies about the Further Comprehensive Use of Waste Resources (Report No. [1996]31), Beijing, China. (in Chinese)

Wu, D., Lin, H., Fang, L., Fu, X., and Wang, Z. (2011). "Effect of silane coupling agent KH-570 on the properties of cassava starch/NR composites," Chemical Engineering 9, 14-16. (in Chinese)

Yang, H., Kim, D., and Lee, Y. (2004). "Possibility of using waste tire composites reinforced with rice straw as construction materials," Bioresource Technology 95, 6165. DOI: 10.1016/j.biortech.2004.02.002

Yao, Y., Cui, Q., Zhao, J., and Wang, X. (2009). "New applications of waste rubber," World Rubber Industry 36(5), 40-46. (in Chinese)

Zhao, J., Wang, X., Chang, J., and Zheng, K. (2008). “Optimization of processing variables in wood-rubber composite panel manufacturing technology," Bioresource Technology 99, 2384-2391. DOI: 10.1016/j.biortech.2007.05.031

Zhao, J., Wang, X. M., Chang, J. M., Yao, Y., and Cui, Q. (2010). "Sound insulation property of wood-waste tire rubber composite," Composites Science and Technology 70, 2033-2038. DOI: 10.1016/j.compscitech.2010.03.015

Article submitted: August 15, 2019; Peer review completed: October 1, 2019; Revised version received: January 29, 2020; Accepted: January 31, 2020; Published: March 16, 2020.

DOI: 10.15376/biores.15.2.3029-3040 